\title{
La ciudad de Lomé. Dos caras del capitalismo urbano periférico
}

\section{Ibán Díaz Parra*}

\section{Resumen}

La urbanización del África occidental, siendo tardía con respecto a la de otros ámbitos, es uno de los procesos más importantes que actualmente acontecen en esta región, de tal forma que cuenta con una de las mayores tasas de crecimiento de población urbana a nivel mundial. Centrándose en el caso de Togo y de su capital, Lomé, el presente trabajo se trata las formas urbanas a las que da lugar el proceso de crecimiento urbano y expansión demográfica en un contexto de estancamiento económico, con especial atención a las estrategias y tácticas desarrolladas por los distintos agentes.

\section{Palabras clave}

Subdesarrollo; Urbanismo Periférico; Segregación Social; Acumulación Por Desposesión; África Occidental; Hábitats Urbanos.

\section{Abstract: City of Lome. Two sides of peripheral capitalism in urban areas.}

The urbanization process in Western Africa started late compared to other areas. However, it is currently one of the most important processes occurring in the region. West Africa has one of the highest urban population growth rates in the world. This study focuses on Lomé, the capital of Togo. It analyzes the types of urban developments resulting from a process of urban growth and demographic expansion in a context of economic stagnation, with a special focus on the tactics and strategies used by the players involved.

\section{Key words}

Underdevelopment; Peripheral Urbanism; Social Segregation; Accumulation By Dispossession; Western Africa; Urban Habitats. 


\section{Introducción}

\section{Justificación y preguntas de partida}

En la primera década del siglo XXI, por primera vez en la historia, la población urbana ha superado a la población rural. Asimismo, el mayor crecimiento de la población urbana se localiza en países periféricos, con un bajo nivel de desarrollo económico y social. La urbanización del África subsahariana, siendo tardía con respecto a la de otros ámbitos, es uno de los procesos más importantes que actualmente acontecen en esta región, de tal forma que cuenta con las mayores tasas de crecimiento de la población urbana a nivel mundial. En este marco es de indudable interés el estudio de una de las regiones del mundo más desconocidas en España, como es el África occidental y en concreto Togo. Por otro lado, para aquellos interesados en el problema urbano y en las cuestiones de justicia social y espacial, la dimensión global de estas problemáticas y el importante papel de la extrema periferia capitalista son hechos ineludibles.

Togo se encuentra en pleno proceso de crecimiento demográfico y expansión urbana volcada sobre su capital, Lomé, que convive con un desarrollo social y humano en regresión y un crecimiento económico prácticamente nulo durante la última década. El estancamiento económico desde la década de 1990 unido al continuo e imparable crecimiento natural y los fuertes procesos de redistribución de efectivos entre el campo y la ciudad, dan lugar a una enorme y desposeída población urbana. Un proceso que excede por completo tanto a la capacidad reguladora del Estado como a la posibilidad de la economía local de absorber mano de obra. Como capital de un país de la extrema periferia capitalista, Lomé supone un enclave de interés para el estudio de las formas particulares que adopta el crecimiento urbano, los procesos de segregación y las estra- tegias de acumulación en este tipo de contextos. Las preguntas fundamentales que se tratan de responder aquí son, en el contexto particular de Togo, ¿a qué tipo de formas urbanas da lugar una región en proceso de crecimiento urbano constante que convive con un desarrollo social regresivo y un crecimiento económico estancado? ¿Qué tipo de estrategias desarrollan los diferentes agentes en la construcción y el habitar de este tipo de ciudad? ¿Cómo afectan los cambios en las estrategias del capitalismo global a este urbanismo del capitalismo periférico?

El presupuesto principal es que a pesar de ser Lome una ciudad que se ha caracterizado históricamente por su falta de segregación sociolaboral, las dinámicas del urbanismo y del crecimiento urbano actual en un marco neoliberal deben tender a procesos segregadores y a formas diferenciadas de construcción de hábitats urbanos en función de la clase social. A pesar de las particularidades del crecimiento urbano de Lomé y de su mercado de suelo, en un contexto capitalista y con una estructura social polarizada, sería esperable encontrar formas de segregación socioeconómica con su origen en estrategias de clase. Al mismo tiempo, las estrategias seguidas deberían reflejar en alguna medida los cambios del capitalismo post-fordista.

\section{Referencias teóricas}

La urbanización del África subsahariana es hoy una cuestión de máxima importancia, más cuando el crecimiento de la población mundial y de los asentamientos humanos se produce principalmente en la periferia de este tipo de espacios. Un tipo de ciudad que tiende a adjetivarse con la valoración politico-económica de la región en la que se ubica. Así, a pesar de la evidente obsolescencia del término "ciudades del tercer mundo", manuales actualizados -y muy recomendables- siguen utilizándolo (Pacione, 2009 o Knox y Pinch, 2009). También es común referir este tipo 
de ciudades con los adjetivos subdesarrollada o en vías de desarrollo. No obstante, algunas de estas ciudades no están evolucionando hacia una situación mejor, sin encontrarse por ello ajenas a procesos de transformación típicamente capitalistas. Debido a esto, aquí, se ha elegido utilizar el término ciudades del capitalismo periférico.

El uso de este término en este texto se aproxima a las teorías del urbanismo dependiente. La teoría de la dependencia explicaba la situación económica periférica de lo que venía a denominarse tercer mundo con respecto a los centros de acumulación de capital occidentales. Una relación de interdependencia dominada por términos de intercambio desigual en la que los países subdesarrollados serían sometidos a una situación de explotación en la cual los centros urbanos regionales jugarían un papel fundamental (Amin, 1976). Wallerstein (2006) reconocería después en su teoría del sistema-mundo un conjunto de relaciones globales más complejo definido por la existencia de un centro dominante, una semiperiferia de países industrializados y una periferia de países pobres. En este contexto, el tamaño, rol y características de las ciudades reflejaría la posición de una sociedad concreta en el sistema. La teoría de la urbanización periférica es una extensión de la teoría de la dependencia y del sistema-mundo y vincula el crecimiento urbano de las áreas periféricas con la difusión del capitalismo global. Esto vendría dado por una variedad de causas. Primero, la destrucción de las formas de producción y comercio precapitalistas tendería a generar una redistribución de efectivos favorable a los centros urbanos. Segundo, los centros urbanos crecerían en función del desarrollo de la actividad industrial y como centros comerciales y de transporte en función de los intereses económicos de las elites locales y extranjeras. Por último, el estado contribuiría también a este crecimiento concentrando las instituciones en la ciudad y generando una burocracia típicamente urbana (Pacione, 2009, p. 461-462).

Algunos autores críticos clásicos han tendido en las últimas décadas a ofrecer una visión más amable y optimista de la evolución de las desigualdades globales (Capel, 2008 y 2010). Desde la década de los noventa, las perspectivas se han vuelto más positivas, tanto por el crecimiento económico, como por la desaceleración del crecimiento de la población urbana en grandes regiones del "tercer mundo", fundamentalmente en América latina (Gilbert, 1993). Sin embargo, el crecimiento de la población sigue siendo muy alto en otras regiones, jugando actualmente un papel fundamental en el África negra, que es la región con la mayor tasa de crecimiento de la población urbana en el mundo y donde son muy pocos los países donde esta tasa se encuentra por debajo del 3.5\% (Pacione, 2009). En el África subsahariana la migración y el crecimiento de las ciudades se ha producido de forma continuada, especialmente a partir de la década de los ochenta, a pesar de una recesión "sostenida y terrible" (Gilbert, 1993).

Samir Amin (1988) proponía a finales de la década de los ochenta la necesidad de que los países subdesarrollados se desconectasen del sistema capitalista mundial para escapar de las relaciones de dependencia. Actualmente, de hecho, mucho autores consideran una gran parte del África subsahariana desconectada del sistema global aunque no exactamente en el sentido expresado por Amin en su libro-, siendo una gran región que habría pasado de la dependencia económica a la irrelevancia (Romero y Nogué, 2008).

Estos países, con un crecimiento económico limitado o nulo y con elevadas tasas de crecimiento de la población, están sufriendo al mismo tiempo un proceso de redistribución de sus efectivos del campo a la ciudad. Un proceso que dista mucho de las migraciones acontecidas en 
los países más desarrollados desde la revolución industrial. Este tipo de migraciones se dirigen a núcleos de población hipertrofiados, donde, a menudo, no existe una demanda de trabajo asalariado que justifique el desplazamiento, ni infraestructuras $\mathrm{o}$ recursos suficientes para racionalizar el crecimiento.

Los cambios producidos en las últimas tres décadas en la práctica política y económica, asociados al auge del neoliberalismo y al régimen de acumulación que ha venido a denominarse postfordismo, habrían tenido también su impacto en los espacios periféricos del capitalismo. Algunos de los procesos más relevantes para la ciudad serían la creciente fragmentación y polarización social (Soja, 2008) y la creciente subordinación de las políticas sociales a las políticas económicas neoliberales (Mayer, 1994).

Siguiendo a Lefebvre (1971) y a Harvey (1977), entre otros autores, la ciudad capitalista sería de partida una ciudad segregada en base a las diferencias de clase, las estrategias de clase y la existencia de un mercado de suelo. Otra forma de distinción social con repercusiones espaciales es el acopio de bienes que garantizan el gusto y la posición del propietario, lo que Bourdieu (2003) denomina capital simbólico y que tiene especial relevancia en cuanto a las características de la vivienda.

Las ciudades del urbanismo periférico, a menudo, han sido caracterizadas por la destacada desigualdad social y la evidente segregación socioespacial de la que hacen gala, un tipo de segregación que habría vinculado en el pasado clase y etnia y que tendría su origen en el proceso colonizador, siendo un caso extremo la denominada ciudad del apartheid (Pacione, 2009, p. 470). Sin embargo, en algunos casos, en concreto Lomé, la elevada oferta de suelo habría dado lugar a unos precios tan bajos que en el contexto post-colonial algunos autores hablan de una ciudad sin segre- gación socioeconómica (Marguerat, 1992 o Agoma, 2009).

Las transformaciones globales a nivel macroeconómico que tenderían a una polarización social de las ciudades (Knox y Pinch, 2009 o Soja, 2008), serían más dramáticas en regiones donde la capacidad de administración es de por sí reducida y las infraestructuras urbanas deficientes. Algunos artículos han observado como la tendencia a la desregularización del capitalismo postfordista y las formas urbanas asociadas pueden profundizar en la injusticia espacial a través una distribución desigual de equipamientos y servicios básicos, como infraestructuras, sanidad, etcétera (Landman, 2002 o Jaglin, 2005). En relación a esto, la multiplicación de las comunidades cerradas sería una expresión extrema de la segregación y la injusticia espacial. La multiplicación reciente de este tipo de comunidades se asocia generalmente a la desigualdad social preexistente y al incremento de la criminalidad. No obstante, pueden considerarse otros factores de la producción y el consumo, como el interés de los promotores y la administración local o el individualismo y el deseo de exclusividad de los consumidores (Janoscka y Glasze, 2003 o Roitman, 1994). Factores estos fruto de las transformaciones en política económica y del cambio cultural que se asocian al auge del capitalismo postfordista (Harvey, 2004 o Christopherson, 1994). Una situación que da lugar a un tipo de espacio urbano que no deja de ser un producto exitoso con proyección global. Un tipo de forma urbana que al mismo tiempo que expresa una segregación social preexistente, tiende a comprenderse como una profundización tanto en la fragmentación social como en la físico-material (Janoscka y Glasze, 2003).

A pesar de que los primeros estudios realizados sobre este tipo de espacios se desarrollaron en occidente, existe una creciente importancia de los 
mismos en países con bajo nivel de desarrollo, de lo que dan testimonio un buen número de trabajos empíricos, especialmente en América latina, pero también en África (Landman, 2002). Es un tipo de arquitectura que ha venido a recibir diversos calificativos, desde arquitectura del miedo a arquitectura bunker (Knox y Pinch, 2009 o Davis, 2003). Mike Davis (2003) tiende a describir estas tendencias como una expresión de la lucha de clases, una acción ofensiva o incluso un golpe de estado por parte de la élite social, sin olvidar que la seguridad privada y la construcción de estos espacios suponen un mercado y un negocio en alza.

Otras características fundamentales del espacio generado a partir del crecimiento urbano en la periferia capitalista, sería el crecimiento caótico y desestructurado de sus periferias. Vinculado a esto, se encuentra la cuestión de la complicada reglamentación del suelo en África, donde solo una parte de las parcelas suelen estar registradas y conviven las formulas del derecho europeo, introducido con la colonización, con el derecho tradicional africano, fuertemente vinculado a formulas de propiedad comunales, lo que da lugar a un mercado altamente irregular y especulativo de suelos que nutre la urbanización. Un mercado que genera la multiplicación de asentamientos informales que escapan a todo control de los Estados (Acicoly, 2007). La regulación de las tierras no sometidas a ningún régimen legal, lo que en la práctica implica su privatización, podría estar suponiendo todavía en la actualidad una importante fuente de acumulación de capital, lo que Harvey también denomina, ampliando el tradicional concepto marxista de acumulación primitiva, acumulación por desposesión (Harvey, 2007).

Independientemente de esta cuestión, el incremento de la población urbana en la periferia capitalista da lugar a la multiplicación de asenta- mientos pobres y superpoblados. El crecimiento urbano, en un contexto de fuertes limitaciones en cuanto a disponibilidad de recursos de todo tipo, hace que la mayoría de las ciudades crezcan fuera de los planes formales y oficiales que regulan el uso del suelo (ONU-Hábitat, 2006). Respecto a las morfologías concretas que adopta este tipo de crecimiento extremadamente irregular, en los últimos años ha venido a popularizarse el uso del término desakota. Con este concepto se hace referencia a formas urbanas fruto de un crecimiento desurbanizado y que resultan en una forma mixta entre lo rural y lo urbano y a penas vinculada a los centros urbanos por medio de ejes de transporte. Próxima al concepto de periurbano, el término desakota implica vastos espacios que cuentan con elementos tanto rurales como urbanos respecto de la vivienda, formas de vida, comunicación, transporte o economía (Davis, 2007 o DST, 2008). En el trabajo Reimagining rural-urban continuum, se llama la atención a propósito de la problemática de la gestión de los recursos en este tipo de espacios. Vinculado a la cuestión de la injusticia espacial, la administración como gestora de recursos tan esenciales como el abastecimiento de luz o agua tiende a colapsarse ante el medio caótico de la desakota. Como resultado, instituciones intermediarias de mercado van tomando roles predominantes en el aprovisionamiento de servicios (DST, 2008).

Comunidades cerradas, autogestionadas y exclusivas por un lado y crecimiento caótico, pseudourbano y fuera de toda regulación por otro, pueden ser vistos como dos formas de crecimiento complementarias de la urbe capitalista periférica. Dos expresiones radicalmente diferentes, a todos los niveles, de una realidad de segregación social extrema y de ausencia de intervención o de capacidad de intervención por parte del agente público respecto de la construcción de ciudad. 


\section{Precisiones sobre la metodología y las fuentes empleadas}

El análisis del medio urbano, ante la ausencia de datos estadísticos fiables, se ha realizado mediante el estudio de la bibliografía existente, la observación directa del espacio urbano y entrevistas con informantes cualificados. Las fuentes estadísticas disponibles son limitadas, dada la antigüedad del último censo de población realizado en el país. Las fuentes de datos estadísticos que se han manejado han sido fundamentalmente las proporcionadas por la Organización de Naciones Unidas (África, a estatistical Yearbook, 2006) y por el Banco Mundial (World Development Indicators 2009). Por otro lado, se ha consultado bibliografía específica sobre Lomé siendo especialmente relevante el trabajo desarrollado por Marguerat (1992 y 1993) y el volumen colectivo Le centenaire de Lomé, capitale du Togo (Marguerat et al, 1998).

Además de las entrevistas realizadas con vecinos del suburbio de Agoe, se han desarrollado cinco entrevistas en profundidad no estructuradas con informantes cualificados, todos ellos vinculados a la administración pública de Lomé, Dirección General de Urbanismo, Universidad de Lomé, Catastro y Servicios de Estadística.

El análisis se desarrolla en dos escala, primero a escala de ciudad, estudiando su crecimiento demográfico, su evolución histórica, la situación de su centro urbano y el crecimiento de su periferia, identificando los principales procesos que se están produciendo en los distintos sectores de la ciudad. En segundo lugar se procede a la descripción de dos sectores urbanos en proceso de expansión y que resultan representativos de los procesos de crecimiento, hábitats, políticas urbanas y estrategias que se están dando en Lomé en la actualidad. El suburbio denominado Agoe, en la periferia norte de la ciudad, y el barrio residencial de la Cite OUA.
En estos sectores urbanos se partirá de un análisis de los espacios público y privado, con objeto de discernir las formas urbanas y hábitats característicos a los que está dando lugar el crecimiento actual de Lomé en su particular coyuntura. El análisis se realiza por medio de un trabajo de campo y observación in situ previos.

\section{Lomé, entre el estancamiento económico y el crecimiento demográfico}

En el popular libro Planet of Slums, Mike Davis apuntaba a la región urbana del Golfo de Guinea como la futura mayor conurbación de infravivienda de todo el planeta (Davis, 2007). Esta conurbación, formada por las urbes de Lagos, Cotonou, Lomé, Accra, Abidján y Dakar se caracteriza por una altísima densidad de población y por su alta tasa de crecimiento (Janssens, 1998).

Dentro de esta región urbana, Lomé, con sus reducidas dimensiones, ha recibido históricamente muy poca atención en comparación con Abidjan o Lagos, las grandes metrópolis de la zona. Esto a pesar de contar actualmente con una tasa de crecimiento notablemente superior y de concentrar una altísima proporción de la población del país, muy por encima del resto de capitales de la región. Una situación de desatención que no ha cambiado con respecto a las quejas que expresaba a este respecto Janssens hace más de una década (ibíd.).

Lomé es una ciudad costera y fronteriza. Emplazada sobre una lengua de arenas con origen en la sedimentación marina y separado el centro urbano de su enorme y creciente periferia por una albufera. Más allá de la laguna, los relieves siguen siendo muy suaves, predominando los suelos arcillosos de las terrazas del río Zio, con su nacimiento en el sistema montañoso de $\mathrm{Fa}$ zao, al noroeste de Lomé. Así, el entorno de Lomé es en su mayor parte una llanura aluvial asociada al curso bajo de este río.

En torno a Lome, como en toda la costa, son 
comunes extensas barras de arena con origen en la sedimentación marina, así como albuferas y rías. Las cotas entre las que se encuentra la ciudad son relativamente bajas. El centro urbano se ubica en torno a los 10 metros por encima del nivel del mar, ganando rápidamente altura conforme la ciudad se extiende hacia el norte, más allá de la laguna. No obstante, en su periferia norte y noreste, asociados al curso bajo del Zio, encontramos grandes extensiones de suelos inundables. Las crecidas del río son comunes en verano, en la estación húmeda característica del clima tropical seco y húmedo de la zona, y tienden a causar terribles daños. En su entorno la colonización se ve seriamente dificultada y los asentamientos ilegales o informales que han aparecido corren serios riesgos de inundación. El propio centro urbano ha sufrido fuertes inundaciones por los desbordamientos del río. La última inundación, en verano de 2009, dio lugar al colapso de la carretera Nacional 1, provocando un prolongado desabastecimiento en la ciudad. En general las lluvias prolongadas de verano, suelen hacer intransitable gran parte de la ciudad, ante el deficiente sistema de drenaje y la ausencia de urbanización.

\section{El crecimiento de la ciudad}

La ciudad surge a partir de un asentamiento ewe del siglo XVIII que es convertido en capital de la colonia alemana de Togolandia en 1897. De una población de apenas 300 habitantes a finales del siglo XIX, Lomé fue incrementando sus dimensiones a partir del asentamiento de inmigrantes atraídos por su dinamismo comercial, potenciado por su ubicación fronteriza y portuaria (Aduayom, 1998). Las tasas de crecimiento se mantuvieron relativamente constantes hasta el final de la Segunda Guerra Mundial. A partir de este momento, y al igual que el resto de ciudades de la región, Lomé comienza a incrementar su población rápidamente con tasas de crecimiento de alrededor del 8.5\% anual. En este periodo, el crecimiento urbano sobrepasa los límites de la ordenada ciudad colonial claramente definidos por el viejo boulevard de circunvalación, desbordándose hacia la albufera. Se trataría de una primera fase de aceleración del crecimiento de la población urbana, fundamentada casi exclusivamente en un saldo migratorio ampliamente positivo (Janssen, 1998).

Según el primer censo nacional, realizado en 1960, Lomé contaba 85.000 habitantes, a penas algo más del $5 \%$ de la población del país. El segundo censo, en 1971, arrojaba un saldo positivo con respecto al primero de 100.000 habitantes, con los cuales Lomé había superado ampliamente sus límites administrativos originales (Marguerat, 1992). Entre los dos primeros censos, se habría producido la mayor densificación del entorno residencial preexistente, agotando prácticamente las posibilidades del espacio entre la frontera con Ghana, la albufera, el distrito industrial al este de la cuidad y la línea de costa. Al mismo tiempo se habría producido la colonización de una amplia franja de terreno al norte de la laguna, en el que era y sigue siendo principal frente de expansión de la ciudad, hacia el noreste, entre las zonas inundables del Zio y los límites fronterizos.

La década de 1970 supone un periodo de reforma interior y auge para la ciudad. Desde los últimos años de la década de los sesenta se produce una fuerte renovación con el levantamiento de nuevas edificaciones, pavimentación de calles, apertura del nuevo mercado central de Lomé, un nuevo cementerio, etcétera. Sería este un periodo en el que también se produce una contundente regulación de la actividad comercial, mercado, bares o servicios de taxi (Amlalo y Gatowonou, 1998). En 1971 se establecen por decreto nuevos límites para la ciudad, quedando notablemente ampliada la municipalidad. En 1974 la recogida y elimina- 
ción de basuras y saneamiento se regula y se encarga a una empresa privada. Sería uno de los primeros países de la región en privatizar este tipo de servicios (ibid.). Así mismo se producen importantes avances en la expansión de la red eléctrica y el incremento de la potencia suministrada (Kouzan, 1998).

El último censo de población realizado, correspondiente a 1981, asignaba 390.000 habitantes a la ciudad (Marguerat, 1992). Entre estos censos se habría producido la anexión de nuevos y grandes espacios, tanto al norte como al este, en torno al distrito industrial-portuario. En términos de espacio construido, la aglomeración habría pasado de menos de 1.000 hectáreas en 1959, a más de 2.000 en 1970 y más de 6.000 en 1981 . No obstante la distribución de la población es sumamente desigual. Actualmente resultan evidentes las fuertes diferencias entres los distritos antiguos, anteriores a 1970, con una elevada densidad de población, y las bajas densidades de los nuevos distritos, donde la colonización se ha realizado con un consumo de suelo mucho mayor (Janssen, 1998).

En contraste con el auge vivido en las décadas de los setenta y ochenta, durante la década de los noventa el país se sumerge en una profunda crisis político-institucional con fuertes repercusiones económicas. Esto afecta notablemente a Lomé, que inicia un lento proceso de decadencia respecto de sus infraestructuras y servicios, a pesar de lo cual su población sigue incrementándose. En este sentido, a finales de la década de 1990, Janssen se preguntaba hasta que punto podía continuar el crecimiento de la ciudad en un contexto de crisis económica como a la que se enfrentaba la población (ibíd.). Sin embargo, desde la década de 1990 el continuo urbano siguió expandiéndose, absorbiendo un gran número de pequeñas localidades rurales que fueron pasando a integrar su aglomeración urbana y que son hoy los suburbios de la ciudad: Agbalépédogan, Akodésséwa, Anfame, Baguida, Kanyikopé, Kélékougan, Lomé II, Totsigan, Totsivi, Djidjolé o Agoe.

En la actualidad, ante la ausencia de censo, los datos son imprecisos, aunque según las estimaciones publicadas por el Banco Mundial, la aglomeración urbana se aproximaría en 2007 a un millón y medio de habitantes. El crecimiento actual es fruto, por un lado, del crecimiento natural, y por otro de la redistribución de efectivos entre el campo y la ciudad. No obstante, y como apunta Janssen, resulta difícil determinar el peso de cada una de estas dinámicas ante la ausencia de censo o registros fiables (ibíd.).

\section{El centro urbano}

El centro urbano de la ciudad se encuentra encajonado entre la frontera con Ghana al oeste, el océano Atlántico al sur y la albufera al norte. Tiene una trama aproximadamente radioconcéntrica, a partir de una gran avenida de circunvalación, el bulevar 13 de Enero, y una serie de avenidas radiales que comunican el centro urbano con las distintas periferias. El centro histórico original queda delimitado por la ronda de circunvalación y la avenida sobre el frente marino. La trama interior del casco cuenta con notables diferencias entre sus sectores oeste y este. El primero cuenta con estructura de ensanche europeo, de grandes bulevares ajardinados, arterias que confluyen en plazas y edificios con un cierto grado de monumentalidad, como el Palacio Presidencial o el Palacio de Congresos. La mitad este cuenta con manzanas de menor tamaño, de planta poligonal y con una cierta regularidad, un continuo seccionado por las grandes avenidas radiales de la estructura general comunicaciones de la ciudad, como la avenida de la Liberation, la rue Mama $n$ Danida, que se convierte al pasar la laguna en el importante boulevard Eyadema, o la Nouvelle Rue de Be. 
Las mencionadas diferencias en la trama tienen su origen en diferencias funcionales. En el sector oeste se localizaba el centro de la administración colonial alemana y francesa, un espacio con baja densidad de población donde se concentraban la práctica totalidad de los edificios de oficinas, embajadas, etcétera. Por su parte, la mitad este concentraba la población autóctona y la verdadera vida de la ciudad, el mercado (Grand Marche) y el cementerio.

Entre el bulevar 13 de Enero y la laguna surge una primera periferia, con un origen todavía anterior a la década de 1970, atravesada por las grandes vías radiales en las cuales se apoya dando lugar a diversos paquetes de trama ortogonal aproximadamente regular. Esto es así, especialmente entre la ronda de circunvalación y la frontera con Ghana, al oeste, barrios de Kodjoviakope y Nyekonakope, donde encontramos también numerosas muestras de la arquitectura colonial alemana o francesa, por lo general en avanzado estado de deterioro. La trama se vuelve mucho más irregular en la primera periferia hacia el este donde se encuentran los barrios de Amoutive y Ablogame.

Tras las reformas modernizadoras de la administración nacional independiente se intervino sobre el viejo sector administrativo-financiero, donde se ubicó el primer palacio presidencial, el palacio de congresos, el estadio de fútbol de la selección nacional (Les Epeviers), zonas ajardinadas y nuevos edificios funcionalistas. Aquí se encuentran algunos de los edificios más altos de África, como el Hotel du 2 Fevrier, primer rascacielos del país, sedes de bancos, edificios ministeriales, embajadas y grandes instalaciones hoteleras en decadencia asociados al auge económico de la década de 1970.

Este sector se encuentra todavía dominado por la presencia de militares y por la actividad gubernativa. Sin embargo, el deterioro ha sido patente en las últimas décadas según los informantes cualificados consultados. A partir de las sucesivas crisis socio-políticas de la década de 1990 el turismo prácticamente desapareció de la ciudad y se redujo el volumen de negocio. A consecuencia de esto el espacio público de la zona adolece de falta de mantenimiento, algo patente en el deficiente acerado y los jardines abandonados. También en la edificación, especialmente en los grandes hoteles funcionalistas, hoy prácticamente en desuso.

La mayor intervención que se está realizando actualmente sobre la zona se centra en el bulevar de la República, avenida sobre la fachada marina de la ciudad, que forma parte del proyecto de carretera interestatal que unirá los distintos núcleos de la gran región urbana del Golfo de Guinea. Sin embargo, en la misma avenida, las casas coloniales se vienen abajo y las viejas infraestructuras de drenaje sufren de falta de mantenimiento y en muchos puntos se encuentran aparentemente colapsadas. La presión demográfica y la febril actividad comercial en el espacio público superan los esfuerzos invertidos en el mantenimiento de las infraestructuras urbanas.

Por lo general, el espacio público, incluso en los sectores más nobles del centro urbano, no cuenta con ningún tipo de mantenimiento, una situación que prolongada en el tiempo ha dado lugar a un espacio extremadamente precario. El acerado se encuentra deteriorado, dañado o casi desaparecido en muchos sectores, el alumbrado público es generalmente insuficiente y el cableado del abastecimiento eléctrico, aéreo y poco seguro. Las redes de abastecimiento y desagüe, heredadas de la etapa colonial, se encuentran muy deterioradas en general, necesitando de urgente rehabilitación o sustitución en algunos casos, de tal forma que hay sectores céntricos de la ciudad donde el abastecimiento de agua ha dejado de 
funcionar.

La ausencia de un sistema eficiente de gestión de residuos sólidos y vertidos es una de las causas principales de esta obsolescencia del sistema de drenaje. Además, esta terrible carencia da lugar a evidentes problemas ambientales en la zona. La acumulación de residuos en las calles es notable, especialmente de plásticos. A esto se le añade el que los vertederos estén integrados en pleno espacio residencial, en extensiones de mayor o menor tamaño. Existen al menos dos vertederos de grandes dimensiones en pleno centro urbano. Además del impacto paisajístico y la demanda de suelo necesaria para acumular estas grandes cantidades de basura, el riesgo para la salud pública es evidente.

\section{La periferia urbana}

El crecimiento urbano encuentra claras barreras que orientan su expansión principalmente hacia el norte. En primer lugar, los límites que encajonan el centro urbano de la ciudad, esto es: la frontera con Ghana, al oeste, y el propio océano, al sur. En segundo lugar, hacia el este, la colonización de nuevos suelos residenciales se encuentra limitada por la presencia de grandes zonas inundables asociadas al río Zio, así como por la ubicación del lago Togo.

De esta forma la ciudad crece principalmente hacia el noroeste, junto a la frontera de Ghana, la zona con las mayores pendientes y a salvo de las inundaciones. La expansión hacia el norte casi ha agotado sus posibilidades y hacia el noreste es inviable sin una contundente obra pública que generase defensas frente a las crecidas del Zio. Hacia el este, por la franja costera, la ciudad crece a duras penas, encajonada entre el océano y la ría.

La expansión de la periferia urbana se fundamenta en varias grandes arterias. Desde la avenida del frente marino, la carretera Nacional 2, hacia el este, donde se concentran las principales funcio- nes productivas: el puerto pesquero y comercial, la refinería, la zona franca y las principales fabricas de manufacturas. En este frente de expansión la ciudad contribuye a la gran conurbación que tiende a dibujarse desde Abidjan hasta Lagos. Hacia el norte, la ciudad se expande a partir de varias grandes avenidas. Por un lado la Nacional 5, que sigue aproximadamente el dibujo de la frontera con Ghana en el extremo oeste del país, comunicando los principales núcleos de población de Fazao. Y por otro lado, la mucho más extensa carretera Nacional 1 que atraviesa el país de norte a sur acompañada por la vieja línea de ferrocarril establecida por los alemanes y que hoy día se dedica casi exclusivamente al tráfico de mercancías.

La colonización de nuevas áreas se realiza en base a contratos privados, a partir de la parcelación que realizan los grandes propietarios y la compra de terrenos por parte de los nuevos colonos. El Estado se limita a legalizar la ocupación y reservar el espacio suficiente para el viario y los servicios fundamentales. La falta de regulación en la ocupación de los nuevos sectores urbanos provoca que, a parte de un viario aproximadamente regular, no pueda encontrarse ningún elemento racionalizador de la extensa periferia de autoconstrucción. Los propietarios que parcelan los terrenos y se enriquecen con el crecimiento de la ciudad, se inhiben en el momento en que recogen los beneficios de la venta y realizan las obligadas cesiones de suelo. El estado por su parte no parece contar con recursos para obligar a los propietarios de suelo a ejecutar la urbanización o para realizarla directamente y se limita a acaparar grandes reservas de suelo en los nuevos terrenos anexionados a la ciudad.

El crecimiento urbano, según los informantes consultados en la Dirección del Catastro, se está realizando fundamentalmente por medio de la 
colonización de suelos agrícolas, de forma no planificada, mediante la parcelación de los mismos por sus propietarios.

Existe una concentración de la propiedad notable en pocas familias, tanto del suelo urbano (donde tiene un enorme peso la relación de alquiler para con la vivienda o el suelo) como para los suelos no urbanos sobre los que se está expandiendo la ciudad en la actualidad. El trabajo de Marguerat señala como la concentración de la propiedad en manos de la burguesía comercial se encuentra en los mismos orígenes de la ciudad. Comerciantes de diverso origen que empezaron a afluir a la urbe desde el momento en que se ubica allí la capital del protectorado alemán, pasando a acumular grandes extensiones de cocoteros que más adelante se convertirán en parte de Lomé o en sus alrededores (Marguerat, 1993). Según Sebald (1998), en el contexto del derecho africano, la mejor manera de poner de relieve un derecho legítimo sobre un terreno sería plantar cultivos perennes. A este respecto, la figura 1 representa el núcleo urbano original de Lomé rodeado de plantaciones de cocoteros que darían lugar a la actual concentración de la propiedad urbana.

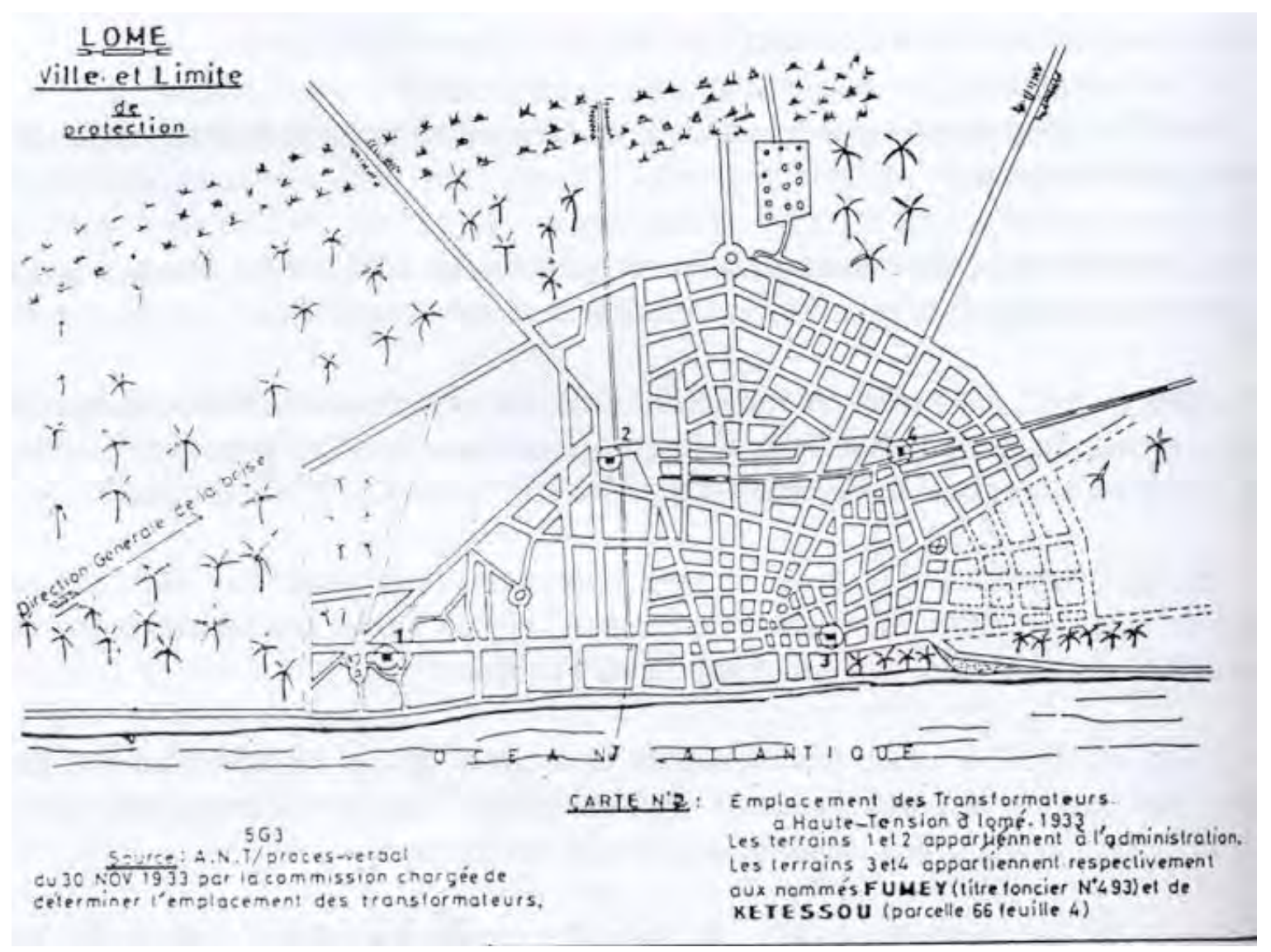

Figura 1. Centro histórico de Lomé. Fuente: Kouzan (1998).

De esta forma, con el desarrollo de la ciudad, muchos comerciantes africanos se ubicaron en las afueras del pequeño puerto de Lomé creando grandes plantaciones enfocadas a la exportación. El derecho de explotación de las tierras se alcan- zaba mediante acuerdo con los jefes locales (ibíd.). A posteriori, la explotación de las tierras otorgaría el derecho a la propiedad absoluta del suelo, con la progresiva privatización del mismo, procurando la consolidación de la posición social 
de una naciente burguesía local.

Con anterioridad a la llegada de colonos europeos no existían documentos legales que atestiguaran derechos de propiedad, y el derecho en la práctica venía dado por el uso y la tradición. La regulación de la propiedad se iniciaría con la colonización, aunque este es un proceso dilatado en el tiempo e inconcluso. En base a la apropiación de hecho, por parte de familias locales, de espacios concretos y más o menos delimitados, los colonizadores empezaron a expedir títulos de propiedad desde finales del siglo XIX. La privatización comenzaría con la regularización de la propiedad del suelo mediante formas propiedad colectiva y propiedades familiares asociadas a un apellido, tierras que podrían ser privatizadas por acuerdo entre los integrantes de la familia. Así, determinadas familias habrían podido acaparar gran cantidad de tierra en la etapa colonial, lo que estaría en el origen de los grandes propietarios de suelo que actualmente se reparten la mayor parte del centro urbano de Lomé y sus frentes de expansión.

La apropiación y la privatización de estas tierras siguen ejecutándose en la actualidad. Los funcionarios del Estado recalcan el hecho de que, al contrario que en otros países, en Togo, el Estado nunca ha pretendido apropiarse de los bienes comunes. Como consecuencia, desde la independencia, ha existido un cierto continuismo con la política colonial tendente al registro de los terrenos y a su privatización.

\section{Cite OUA y Agoe, expresiones extremas del capitalismo urbano de Lomé}

Cite Oua y Agoe (figura 2) son dos espacios con pocas características en común, a parte de tratarse de sectores que han sido sumados a la ciudad de Lomé en los últimos quince años. Dos espacios de colonización reciente que expresan dos formas radicalmente distintas de construir ciudad. Oua es un espacio excepcional dentro de la urbe, la mayor intervención urbanística, planificada y promovida desde el sector público. Agoe, por el contrario es un suburbio más, un espacio banal en cuanto a la expansión de Lomé, que resulta representativo de la forma en la que se está fundamentado este crecimiento, de forma ajena por completo a la planificación y al control del agente público. Ambos, sin embargo, son espacios que reflejan aspectos de una misma realidad urbana.

\section{Cite OUA 2000}

Cite OUA se engloba en un proyecto para la creación de un nuevo desarrollo urbano con cierta centralidad. Surge a partir de la cita de la Organización para la Unidad Africana en 2000 y sobre suelos expropiados por el Estado, entre el campus universitario y el aeropuerto. El objetivo de la operación sería generar un nuevo centro administrativo para la ciudad, teóricamente justificado por la necesidad de descongestionar el centro existente deslocalizando algunas funciones públicas. El proyecto incluye un desarrollo residencial de élite que es el principal interés de éste epígrafe. El nombre completo del proyecto es Cite OUA 2000, diseñado como la operación más ambiciosa a nivel urbanístico promovida por la administración en la última década y todavía en curso en la actualidad. El espacio se localiza al noreste del centro urbano, más allá de la laguna pero bien comunicada gracias a su ubicación sobre el eje fundamental que supone el boulevard Eyadema, que se prolonga hacia el sur penetrando en el centro urbano y hacia el norte convirtiéndose en la carretera Nacional 1. Además cuenta con una buena conexión y proximidad con el aeropuerto de Lome, que prácticamente quedaría integrado en el conjunto. 

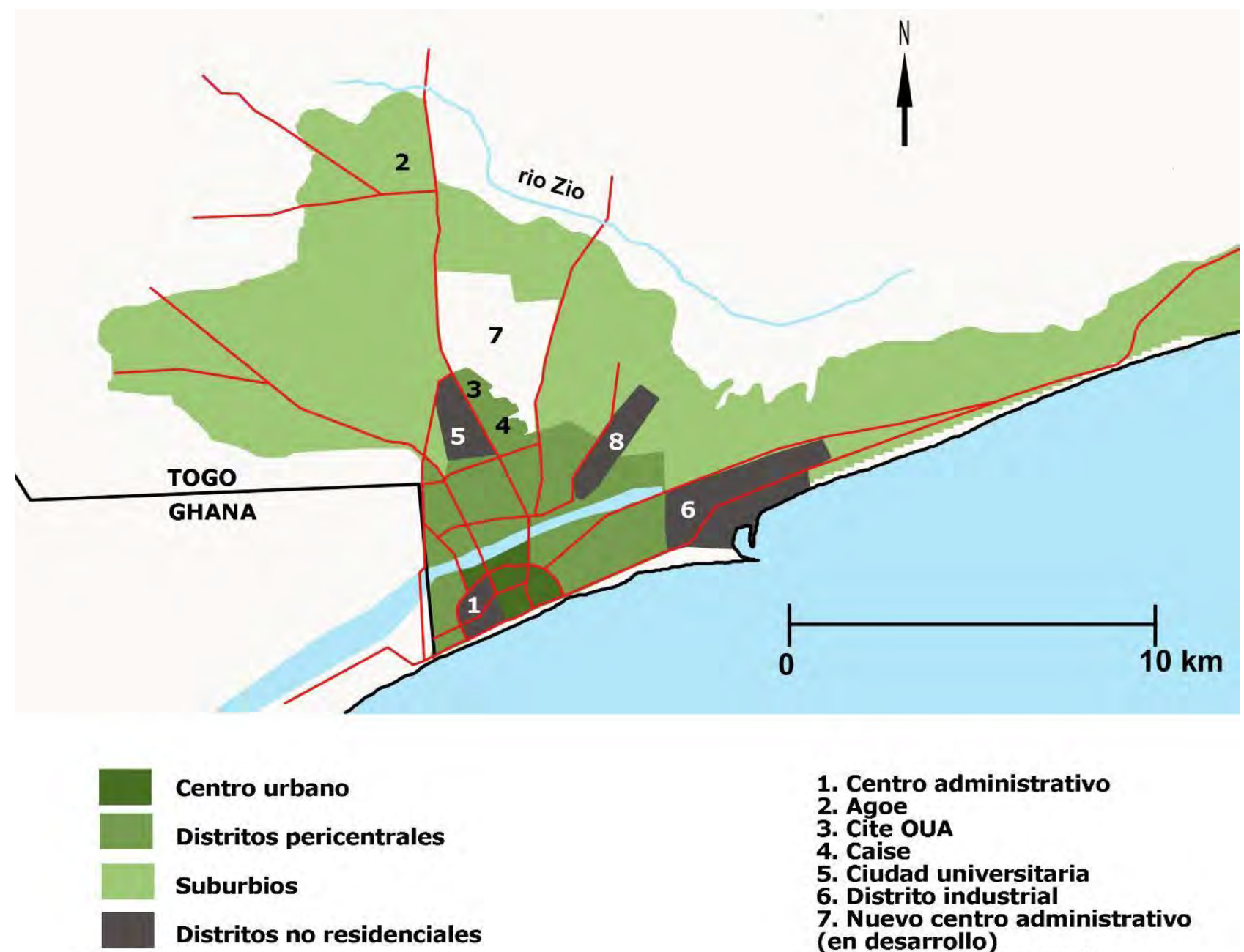

\section{Centro urbano}

Distritos pericentrales

Suburbios

Distritos no residenciales
1. Centro administrativo

2. Agoe

3. Cite OUA

4. Caise

5. Ciudad universitaria

6. Distrito industrial

7. Nuevo centro administrativo

(en desarrollo)

8. Aeropuerto de Lomé

Figura 2. Lomé, centro urbano y suburbios. Fuente: Elaboración propia a partir de Gervais-Lambony (2007).

Junto al espacio residencial se encuentran las embajadas de EEUU y China. Estas dos embajadas, de forma simbólica, se encuentran próximas y miran al palacio presidencial, el edificio de mayores dimensiones de todo el conjunto, terminado en los últimos años. Frente a él está la gran mezquita financiada por el gobierno Libio. En el extremo norte, se localiza la sede de Togotelecom, una de las mayores empresas públicas de Togo y la de su filial de telefonía móvil, Togocel. Sobre el boulevard Eyadema se encuentran también un buen número de edificios de la administración pública, que incluyen ministerios, la administración de la lotería nacional y la administración de la Zona Franca. Todo ello interrumpido por grandes espacios abiertos, diáfanos y ajardinados, todavía en proceso de desarrollo.
La Cite OUA, adopta el modelo de urbanización cerrada. El acceso ha de realizarse desde el boulevard Eyadema. Allí una amplia muralla hace que se entre mediante un par de vías fuertemente vigiladas por militares. La militarización del espacio no acaba aquí. En la entrada principal a la urbanización, el primer edificio que encontramos es la sede del Ministerio de Defensa y en las poco transitadas calles de la urbanización es común encontrar militares de servicio o seguridad privada custodiando los edificios.

La edificación existente es de estilo europeo, con predominio de tejados rojizos a dos aguas, de teja francesa, cromatismos claros, blanco o tonos pastel y balconadas de grandes dimensiones. Denota un cierto gusto por el historicismo que recuerda también a la elite social occidental, 
representado por la aparición de columnas griegas y frontones triangulares. Lo que más las diferencia de las edificaciones de tipo mansión que pueden encontrarse en el resto de la ciudad, además de su concentración y segregación, es el buen gusto estético. La ostentación se realiza aquí por medio de edificaciones unifamiliares de grandes dimensiones y buenos materiales, fuertemente vigiladas, más que mediante los diseños y cromatismos llamativos que son comunes en los edificios residenciales de calidad dispersos por la ciudad. La élite económico-cultural se refugia así tanto de la pobreza como de la ostentación vulgar y de dudoso gusto.

El espacio privado destaca por el lujo de sus edificaciones de varias plantas protegidas de los ojos curiosos por altos muros, a menudo culminados en alambre de espino y cámaras de seguridad. Aunque las edificaciones están personalizadas, conservan ciertos elementos comunes que otorgan homogeneidad al conjunto.

Por su parte, el espacio público es sobrio y bien tratado, con aceras anchas, de entre tres y cinco metros, y arbolado de gran porte sobre alcorques. En las calles más anchas la doble dirección es separada por arriates ajardinados con árboles tropicales que otorgan cierto aspecto de boulevard. Por otro lado, como sector residencial, carece por completo de tiendas y prácticamente de vida en la calle.

Al mismo tiempo que se trata de un espacio fundamentalmente residencial, la dependencia total del automóvil para los desplazamientos genera un espacio público meramente ornamental. La mayor actividad en la vía pública viene dada por la gran cantidad de asalariados vinculados a la seguridad, aunque también a la limpieza o la jardinería, que pueblan las calles en las inmediaciones de las entradas a las mansiones. Aquí el proceso de urbanización se ha realizado con carácter previo a la edificación o de forma simultánea. Varias nuevas edificaciones se están levantando y otras parcelas esperan su construcción, mientras la urbanización del espacio público avanza pareja o con ventaja. Aquí y allá aparecen rotondas ajardinadas y verde urbano, menos abundante que en otros espacios de la ciudad donde éste tiene un origen salvaje, pero con tratamiento, ubicados en bancales o alcorques y acompañados por setos. El buen estado de las redes de drenaje y acerado y el alumbrado público abundante son también una excepción en el conjunto de la ciudad.

\section{Agoe}

Agoe es uno más de los núcleos rurales absorbidos por el crecimiento urbano de Lomé. Se sitúa al norte de la ciudad, junto a la N1, a 6 kilómetros de la Cite OUA sobre el boulevard Eyadema y a 12 kilómetros del centro urbano. Al contrario que Cite OUA, es el tipo de espacio usual que produce la expansión de Lome. Frente a lo excepcional y exclusivo de la urbanización cerrada en el conjunto urbano, Agoe no deja de ser un espacio totalmente banal. De igual forma, es un espacio ajeno a la marcada segregación que expresan barriadas como Cite OUA. No es un espacio de elite sin ser ni mucho menos un espacio marginal, y en la variedad de sus viviendas podemos comprobar la variedad de la composición social de la ciudad. Un espacio heterogéneo social y funcionalmente.

Como paisaje urbano, la cuestión más reseñable de Agoe es la influencia rural y natural, todavía fuerte. Existen edificaciones de carácter rural y tradicional, las típicas pallozas de adobe y paja y no son extraños huertos entre el espacio edificado. Se trata de un espacio con vegetación apabullante, el verde urbano aparece aquí y allá, abundante, espontaneo y autóctono, sin tratamiento alguno. La vegetación previa queda atrapada como vestigio del espacio natural que es sustituido por un espacio humanizado. 
Sin embargo, fuera de las características rurales que pueda todavía contener se trata de un espacio totalmente absorbido e integrado en el continuo urbano de Lomé, que prosigue actualmente su expansión hacia el norte. Un espacio copado por la edificación residencial, con calles espaciosas inundadas por el comercio y por pequeños talleres de distinto tipo.

Las edificaciones suelen ser de una planta, las más comunes y humildes, aunque algunas edificaciones de mayor calidad pueden llegar hasta las tres plantas. El patio suele contener algo de vegetación ornamental, un pozo y un corral con animales de granja.

Una primera diferenciación que debe realizarse es entre viviendas unifamiliares y casas comunales. En las segundas, la construcción de nuevos módulos, a menudo, deja tan solo un estrecho pasillo al aire libre que se dirige a la entrada de la parcela. Aquí, las viviendas se ven reducidas a su mínima expresión, mientras en el espacio común se realiza la vida colectiva y las principales actividades domésticas. Los elementos comunes esenciales suelen ser el pozo, que tiende a ocupar un lugar central en la parcela, y los aseos comunes, una poza séptica que suele ubicarse en un extremo de la parcela, con una pequeña casetilla anexa al muro perimetral. La edificación tiende a ser pobre en ornamentos, con fachada enfoscada y pintada de blanco. Son edificios de autoconstrucción sobrios y sin ningún adorno, con materiales variados, a veces dentro de una misma construcción: adobe, ladrillo, bloques de hormigón, uralita, etcétera.

Sin muros perimetrales y, generalmente, fuera de la alineación de las calles, encontramos grupos de viviendas de estructura aparentemente menos consolidada. Edificios de reducidas dimensiones, de ladrillos de barro cocido de forma artesanal, generalmente de planta rectangular, aunque también pueden encontrarse construcciones de planta circular, y culminadas en tejados de uralita o paja. Los informantes consultados señalan que este tipo de viviendas son fruto de la ocupación espontánea de suelo, lo que determina la poca consolidación y la provisionalidad de la estructura. Por debajo de estas estructuras, en cuanto a consolidación y habitabilidad, quedarían las chabolas, que en esta zona se asocian, más que a viviendas, a espacios comerciales.

En el otro extremo de este tipo de edificaciones están las ostentosas viviendas unifamiliares de las familias acomodadas, que encontramos en buen número en Agoe. Así, coexisten desde viviendas de autopromoción de dimensiones medias a palacetes de grandes dimensiones. Indistintamente, suelen ubicarse tras un alto muro de hormigón con algún tipo de decoración y culminado en alambre de espino, tras el cual es común encontrar una hilera de sauces o algún otro tipo de arboles de gran porte, que contribuyen a separar la vivienda de la vía pública. Destacan frente al resto de viviendas por sus grandes dimensiones y por el variado uso de materiales y cromatismos, así como por adoptar formas arquitectónicas que escapan de lo tradicional y lo convencional. En ellas encontramos teja francesa y árabe, balaustradas, balcones voladizos, falso ladrillo o alicatados de motivos llamativos.

La heterogeneidad de este espacio residencial puede contemplarse en la figura 3 . 


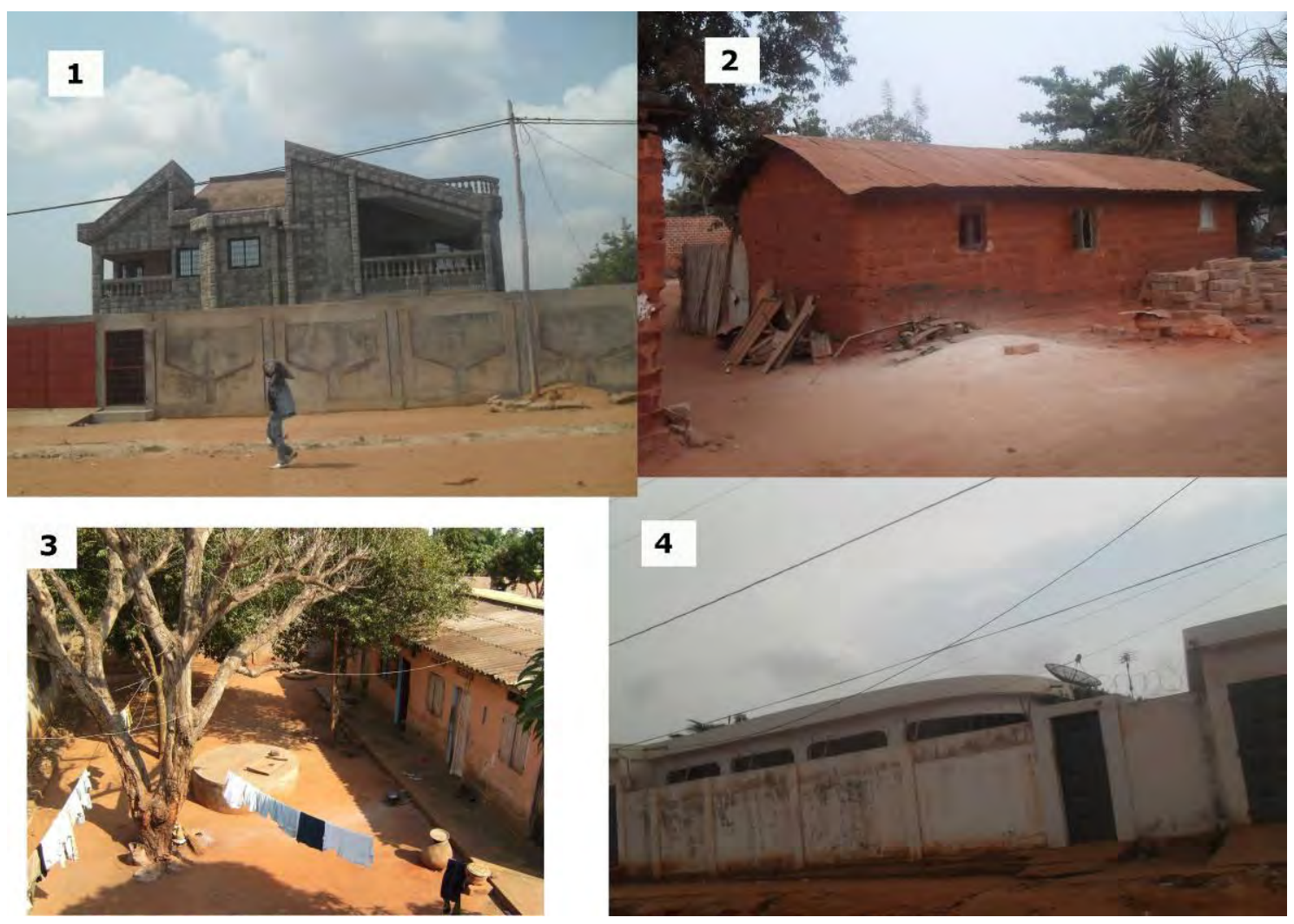

1. Vivienda ostentosa de élite. 2. Autoconstrucción sobre suelo ocupado. 3. Interior de una casa comunal. 4. Vivienda familiar con características de bunker.

Figura 3. Variedad de la edificación residencial en Agoe. Fuente: Elaboración propia.

El espacio público está definido por amplísimas avenidas que pueden alcanzar hasta los 50 metros de ancho. La expropiación de suelo para viario y dotaciones permite contar con este tipo de vías. Se trata de enormes avenidas de tierra rojiza, arcillosa, donde se ha suprimido la cubierta vegetal y donde, en el mejor de los casos, se ha compactado la tierra para generar un firme aproximadamente regular.

La anchura de las calles permite la ocupación de una gran parte de la vía pública por la actividad comercial. Los límites laterales de las principales avenidas vienen prácticamente definidos por los quioscos, chamizos de madera y pallozas destinadas al comercio, así como por los soportales y las terrazas que tienen su origen en edificaciones más estables. Este amplio viario soporta a diario un intenso tráfico protagonizado principalmente por motocicletas, muchas de ellas mototaxis, y por algunos automóviles. El tráfico motorizado es efectivamente caótico, pero no tan problemático como en el resto de la ciudad. Aún así, el continuo desplazamiento da lugar a una permanente polvareda en la calle, que hace que edificaciones y vegetación adopten el color rojizo propio del suelo. A la ausencia de tratamiento del viario, se le suma la ausencia de semáforos o señalización de tráfico. Estas carencias se extienden a la falta de alumbrado público de cualquier tipo, lo que limita enormemente la vida en la calle fuera de las horas de día. La red de abastecimiento, aérea y precaria, se limita a proporcionar electricidad, careciendo de cualquier tipo de red de suministro de agua o de drenaje, dependiendo gran parte de la población del mercado privado para obtener agua.

Ante la ausencia de urbanización pública, es común que la clase acomodada complemente la 
ostentación de la que hace gala su arquitectura con la urbanización de estrechas franjas de viario, delante de sus muros perimetrales. Una urbanización privada, que consiste en la instalación de un talud de hormigón frente a la fachada de la casa, a modo de acera, que facilita el acceso al interior de la propiedad. Sin embargo, es también común encontrar intervenciones más refinadas, en las que los propietarios privados intervienen sobre el espacio público, realizando una cierta apropiación del mismo, creando pequeñas aceras, con arriates, alcorques y vegetación con tratamiento. Una táctica, que además de mejorar la habitabilidad del conjunto edificatorio contribuye a la proyección de la vivienda hacia el espacio

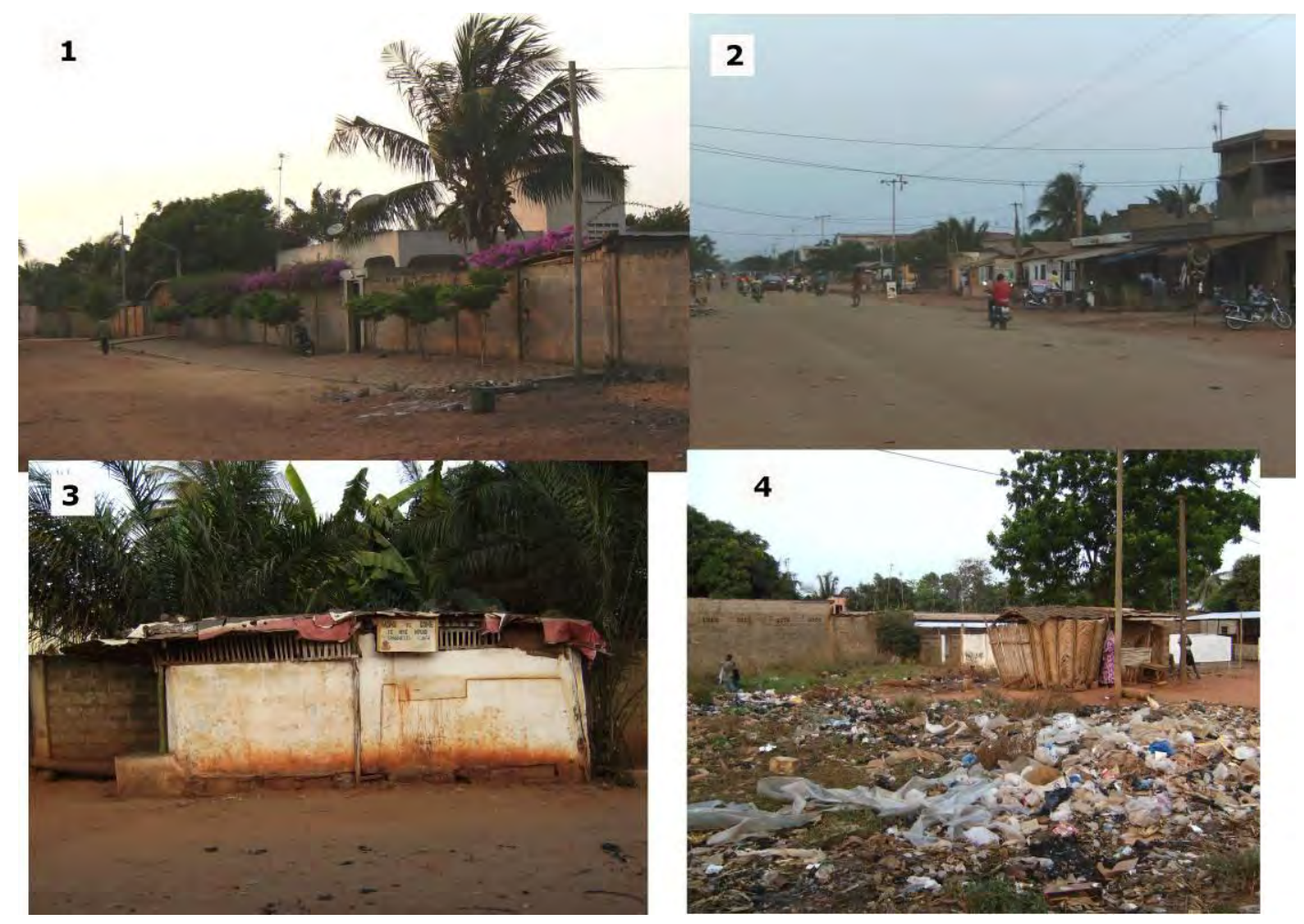

1. Autourbanización. 2. Moto-taxis. 3. Kiosco-restaurante ocupando la vía pública.

4. Acumulación de basuras en la vía pública.

Figura 4. Espacio público en Agoe. Fuente: Elaboración propia .

\section{Conclusiones. Espacios urbanos polarizados}

El nuevo medio urbano generado en Lomé tiene su origen en un contexto de estancamiento económico, fuerte crecimiento natural de la público.

A la ausencia de infraestructuras se le suma la ausencia de servicios básicos, y la ausencia más fácilmente apreciable es la carencia de un sistema de recogida de basuras. Envases de todo tipo, fruto de la actividad comercial y el consumo familiar, se acumulan por todas partes cubriendo a veces tramos de calle enteros y dificultando la circulación. El único tratamiento que le pueden dar los vecinos es la quema por las noches o su acumulación en zanjas cavadas para tal propósito. Sin embargo estos tratamientos desorganizados son a todas luces insuficientes, como puede observarse en la figura 4. 
del centro urbano encuentra su reflejo en una periferia donde la precariedad de gran parte de la edificación residencial construida se ve agravada por la ausencia total de urbanización y de servicios públicos. Al mismo tiempo, el medio urbano construido expresa tanto el enriquecimiento de una elite social togolesa como la concentración progresiva de una población sin apenas recursos. Agoe y OUA son espacios radicalmente distintos pero producto de una misma lógica sistémica, la de la urbanización capitalista en su expresión periférica. Las formas de este capitalismo urbano periférico se concretan en un crecimiento caótico, desestructurado y ajeno en gran medida a un control centralizado de cualquier tipo, que da lugar, tanto a formas mixtas entre lo rural y lo urbano, como a guetos de grupos privilegiados fuertemente vigilados, forma, esta última, importada de los espacios centrales del capitalismo global. Mientras en el primer tipo de espacio urbano se refleja el bajo nivel de segregación al que hacía referencia Marguerat, en el segundo, la urbanización cerrada irrumpe generando una segregación extrema.

La desigualdad social existente da lugar a una injusticia espacial patente expresada en sectores urbanos radicalmente diferentes. Por un lado, espacios de precariedad, donde la presión demográfica y la economía informal dan lugar a un espacio público muy activo. Por otro lado, espacios de abundancia, pero al mismo tiempo fenecidos como espacios públicos, donde se combina la homogeneidad social con la monofuncionalidad y con una progresiva militarización del entorno.

En conclusión, las estrategias de clase marcan actualmente el crecimiento de la ciudad, tanto en la acumulación por desposesión, mediante la privatización de los bienes comunales en la periferia urbana, como en la estrategia de desarrollo de un nuevo centro urbano en Cité OUA. Aquí, a la estrategia de acumulación se le suma la búsqueda de la separación y la distinción social mediante la creación de un enclave de elite.

Fuera de los reducidos enclaves privilegiados, las particularidades de la gestión y propiedad del suelo urbano parecen conducir a un bajo grado de segregación social. Así, la mayor expresión de la segregación no se muestra en la conformación de unidades espaciales con caracterización sociolaboral radicalmente diferente sino en la propia diferenciación de las parcelas privadas, en la contraposición de las residencias de familias acomodadas frente a las edificaciones colectivas. De esta forma, los dispositivos de seguridad y de delimitación de la propiedad son los que generan un tipo de diferenciación y separación entre clases.

Respecto de la política urbana, en un contexto de desigualdad social, ante la falta de intervención del Estado, el crecimiento urbano genera injusticia espacial en materias tan básicas como el abastecimiento de agua. Frente a esto, resulta una obviedad que la responsabilidad de la urbanización de los sectores en expansión de la ciudad, debería recaer sobre los grandes propietarios de suelo, los mismos propietarios que están recogiendo los beneficios del crecimiento de la urbe. No obstante, es el Estado el que debe encargarse de vigilar por que estas plusvalías reviertan en el beneficio de la comunidad, en algo tan esencial como es la urbanización mínima de los nuevos lienzos de ciudad.

Por otro lado, el urbanismo por proyectos como estrategia, abandona tanto los principales frentes de expansión de la ciudad, como la rehabilitación de los espacios consolidados y envejecidos. Tenga o no tenga éxito Cité OUA, urbanísticamente supone la renuncia a intervenir sobre un centro urbano, de grandes dimensiones, complejo y demandante de recursos para su rehabilitación, abandonando las posibilidades del frente marino como espacio central de la ciudad. Así, el benefi- 
cio de esta estrategia no deja de ser relativo, puesto que las medidas que no se adopten respecto de la expansión urbana y el deterioro del centro, serán la herencia del futuro. Las estructuras espontaneas e infradotadas establecidas, serán difíciles de modificar o cambiar y la infraestructura que se pierda en el decadente devenir del centro urbano será difícil de recuperar.

El modelo político adoptado a propósito del crecimiento de la ciudad resulta especialmente positivo a la acumulación de capitales privados en el mercado de suelo por medio de un proceso de acumulación por desposesión, al mismo tiempo que favorece fundamentalmente los hábitats de elite social. Este tipo de políticas no son en ningún caso exclusivas de países periféricos y se enmarcan en un contexto ideológico más amplio y hegemónico en la actualidad. En términos generales, a parte de los condicionantes particulares de la región, las estrategias adoptadas coinciden con las hegemónicas de capitalismo neoliberal, acumulación por desposesión, privatización, desatención de las cuestiones sociales y urbanismo por proyectos; y las formas resultantes, formas urbanas globalizadas: comunidades cerradas y urbanismo desurbanizado, formas híbridas entre lo rural y lo urbano o desakotas.

\section{Referencias}

ADUAYOM, Messan Adimado. Lome, une capitale frontiere. Implications socio-économiques et politiques. En GAYIBOR, Nicoué, MARGUERAT, Yves y NYASSOGBO, Kwami. Le centenaire de Lomé, capitale du Togo (1897-1997), Actes du colloque de Lomé (3-6 mars 1997). Lomé: Presses de l'UB, 1998, p. 289-302.

AGOMA, Blandine. Territorios e identidades en Lomé (Togo). Proceso de categorización, dinámicas espacio-residenciales y lógicas del lugar. Revista Ressac, 2009, n ${ }^{\circ} 2$.

AMIN, Samir. Unequal Development: An Essay on the Social Formations of Peripheral Capitalism. New York: Monthly Review Press, 1976. 440 p. AMIN, Samir. La desconexión, hacia un sistema mundial policéntrico. Madrid: IEPALA, 1988. 357 p.

AMLALO, Sédo y GATOWONOU Theodore. L'organisation administrative de Lome de 1897 a nos jours. En GAYIBOR, Nicoué, MARGUERAT, Yves y NYASSOGBO, Kwami. Le centenaire de Lomé, capitale du Togo (1897-1997), Actes du colloque de Lomé (3-6 mars 1997). Lomé: Presses de l'UB, 1998, p. 111-124.

ACIOLY, Claudio. El desafío de la formación de asentamientos informales en los países en vías de desarrollo. Land Lineas, 2007, vol. 19, n 2.

BOURDIEU, Pierre. Las estructuras sociales de la economía. Barcelona: Anagrama, 2003. 282 p.

CAPEL, Horacio. Continuar y superar a Milton Santos. En MENDOZA, Cristobal (coord.). Tras las huellas de Milton Santos. Una mirada latinoamericana a la geografía humana contemporánea. México: Anthropos, 2008.

CAPEL, Horacio. Urbanización Generalizada, derecho a la ciudad y derecho para la ciudad. Conferencia inaugural del XI Coloquio Internacional de Geocrítica. Scripta Nova. Revista Electrónica de Geografía y Ciencias Sociales, Universidad de Barcelona, 1 de agosto de 2010, vol. XIV, $\quad n^{\circ} \quad 331$

<http://www.ub.es/geocrit/sn/sn-331/sn-331-

7.htm>. (Consultado el 15 de marzo de 2011).

CHRISTOPHERSON, Susan. The Fortress City: Privatized Spaces, Consumer Citizenship. En AMIN, Ash. Post-fordism. A reader. Oxford: Blackwell Publishers, 1994, p. 409-432.

DAVIS, Mike. Ciudad de cuarzo. Arqueología del futuro en Los Ángeles. Madrid: Lengua de Trapo, 2003. 387 p.

DAVIS, Mike. Planeta de ciudades miseria. Madrid: Foca, 2007. 283 p.

DST (DESAKOTA STUDY TEAM). Reimagining 
the rural-urban continuum. Kathmandu: ISET, 2008. $23 \mathrm{p}$

GAYIBOR, Nikoué Lodjou y KOSSI-TITRIKOU, Komi. Stratégies lignagéres et occupaton de l'espace. Revue Française d'Histoire d'Outremer, 1999, Tome 86, n³24-325, p.203-228.

GERVAIS-LAMBONY, Philippe. (Ed.). Lomé. Dynamiques d'une ville africaine. Lomé: Karthala, 2007. 326 p.

GILBERT, Alan. Ciudades del Tercer Mundo: la evolución del sistema nacional de asentamientos. Eure. Revista Latinoamericana de Estudios Urbano Regionales, Julio de 1993, vol. 16, $n^{\circ}$ 56, p.41-58.

HARVEY, David. Ciudad y justicia social. Barcelona: Siglo XXI, 1977.

HARVEY, David. La condición de la postmodernidad. Investigación sobre los orígenes del cambio cultural. Buenos Aires: Amorrortu Editores, 2004. $408 \mathrm{p}$.

HARVEY, David. Espacios del Capital. Hacia una geografía crítica. Madrid: Akal S.A., 2007. 445 p.

IGI (ICON GROUP INTERNATIONAL INC.), Executive report on strategies on Togo, IGI, 2000.

<http://www.tradebit.com/filedetail.php/1097586

73-executive-report-on-strategies-in-togo->.

JANOSCHKA, Michael y GLASZE, Georg. Urbanizaciones cerradas. Un modelo analítico. Ciudades, Julio-septiembre de 2003, n 59, p. 9-20.

JANSSENS, Marja. Lomé, 100 ans de croissance demographique. En GAYIBOR, Nicoué, MARGUERAT, Yves y NYASSOGBO, Kwami. Le centenaire de Lomé, capitale du Togo (18971997), Actes du colloque de Lomé (3-6 mars 1997). Lomé: Presses de l'UB, 1998, p. 303314.

JAGLIN Sylvie. Los servicios urbanos de agua ante la heterogeneidad social en las ciudades de África subsahariana: ¿hacia una ingeniería espacial de la diversidad? Cuadernos Interna- cionales de Tecnología para el Desarrollo Humano, 2005, n³, p. 16.

NOX, Paul y PINCH, Steven. Urban Social Geography: An Introduction. Essex: Prentice-Hall, 2009.

OUZAN, Komlan. L'evolution de l'electrification de Lomé et des ses environs de 1925 a nos jours. En GAYIBOR, Nicoué, MARGUERAT, Yves y NYASSOGBO, Kwami. Le centenaire de Lomé, capitale du Togo (1897-1997), Actes du colloque de Lomé (3-6 mars 1997). Lomé: Presses de l'UB, 1998, p. 125-140.

LANDMAN, Karina. Gated communities in South Africa. En VVAA. Informe de Valladolid 2002. Los derechos humanos y la ciudad. Valladolid: Universidad de Valladolid, 2002, p. 23-27.

LEFEBVRE, Henri. De lo rural a lo urbano. Barcelona: Península, 1971. 268 p.

MAYER, Margit. Post-fordist city politics. En AMIN, Ash. Post-fordism. A reader. Oxford: Blackwell Publishers, 1994, p. 316-338.

MARGUERAT, Yves. Une brève histoire de la capitale du Togo. Lomé: Karthala, 1992. 64 p.

MARGUERAT, Yves. Dynamique urbaine, jeunesse et histoire au Togo. Lomé: Presses de I'UB, 1993.

MARGUERAT, Yves. Les deux Naissances de Lome: une analyse critique des sources. En GAYIBOR, Nicoué, MARGUERAT, Yves y NYASSOGBO, Kwami. Le centenaire de Lomé, capitale du Togo (1897-1997), Actes du colloque de Lomé (3-6 mars 1997). Lomé: Presses de l'UB, 1998, p. 303-314.

ONU. Africa, a estatistical Yearbook, ONU, 2006. < http://www.uneca.org/statistics/asybright.htm>. ONU-Habitat. State of the world's cities 2006. Londres: Earthscan, 2006. 204 p.

PACIONE, Michael. Urban Geography. A global perspective. Oxford: Routledge, 2009. 720 p.

ROITMAN, Sonia. Urbanizaciones cerradas: estado de la cuestión hoy y propuesta teórica. 
Revista de Geografía Norte Grande, Diciembre de $1994, n^{\circ} 3$, p. 5-19.

ROMERO, Joan y NOGUÉ, Joan. Globalización y nuevo desorden mundial. En ROMERO, Joan. Geografía humana. Procesos, riesgos e incertidumbres en un mundo globalizado. Barcelona: Ariel, 2008.

SEBALD, Peter. Les espaces verts a Lome au cours de la periode allemande. En GAYIBOR, Nicoué, MARGUERAT, Yves y NYASSOGBO, Kwami. Le centenaire de Lomé, capitale du Togo (1897-1997), Actes du colloque de Lomé (3-6 mars 1997). Lomé: Presses de l'UB, 1998, p. $125-140$.

SOJA, Edward. Postmetropolis. Estudios críticos sobre las ciudades y las regiones. Madrid: Traficantes de sueños, 2008. 600 p.

WALLERSTEIN, Immanuel. Análisis del sistemamundo. México: Siglo XXI, 2006. 153 p.

\section{Cita del artículo}

DÍAZ PARRA, I. La ciudad de Lomé. Dos caras del capitalismo urbano periférico. Hábitat y sociedad, 2011, $\mathrm{n}^{\circ} 2$, p. 131-151. <www.habitatysociedad.us.es>.

http://dx.doi.org/10.12795/HabitatySociedad.2011.i2.07 